\title{
Participação do Brasil na grande revolução das Geociências
}

\author{
Fernando Flávio Marques de Almeida \\ Escola Politécnica (aposentado) \\ Universidade de São Paulo - USP \\ ffma@uol.com.br
}

Almeida, F.F.M. de. 2005. Participação do Brasil na grande revolução das Geociências. Terræ Didatica, 1(1):44-49. <http:// www.ige.unicamp.br/ terraedidatica/>
O paralelismo entre as costas das Américas e da Europa-África já havia chamado a atenção do filósofo inglês "Sir" Francis Bacon, que ainda em 1620 referiu-se à possibilidade de que tivessem estado ligadas. Em fins do século XIX geólogos haviam sugerido o deslocamento dos continentes, assim como sua aglutinação, como a Terra de Gondwana proposta pelo geólogo austríaco Eduard Suess (1895). Coube, entretanto, ao astrônomo e meteorologista alemão Alfred Lothar Wegener formular uma hipótese global, geologicamente bem fundamentada, em artigo datado de 1912, três anos depois desenvolvida no livro em alemão $A$ Origem dos Continentes e Oceanos. Wegener baseou-se nos conhecimentos geológicos, paleontológicos e paleoclimáticos então disponíveis, assim como na geometria dos continentes. Supôs ter existido no passado um megacontinente ao qual denominou Pangéia, que no Jurássico passou a se fraturar, tendo os fragmentos derivado para originar os continentes atuais. A hipótese, estranha para os conhecimentos da época, sofreu restrições, sobretudo pelos geofísicos. Wegener não pôde explicar como os continentes poderiam se mover nos fundos oceânicos rígidos e qual seria a força capaz de deslocá-los. Em 1927 o geólogo sulafricano A. Du Toit, após visitar o Brasil, publicou seu conhecido livro $A$ Geological Comparison of South America with South Africa no qual apontava diversas semelhanças entre a geologia dos dois continentes. No final daquele ano o ilustre geólogo inglês Arthur Holmes muito cautelosamente sugeriu na Sociedade Geológica de Edimburgo que, aquecido pelo calor do interior da Terra, o manto sólido poderia adquirir certa viscosidade que permitiria a formação de correntes de convecção que, em sua ascensão, romperiam a crosta e arrastariam seus fragmentos, idéia que exasperou eminentes geólogos, mas que o tornou verdadeiro precursor da teoria da tectônica de placas. Apesar dos novos fatos e suposições a hipótese de Wegener continuou em descrença, 
e achava-se quase descartada, sobretudo na América do Norte, após seu falecimento ao se perder nas geleiras da Groenlândia em 1930. Contudo, com sua hipótese lançara a semente do que viria a se tornar, em meados do século, a maior revolução havida nas Ciências da Terra.

O interesse pela teoria ressurgiu na década de 1950 com a exploração dos fundos oceânicos levando à identificação de longas cadeias de montanhas perfazendo no total cerca de $80.000 \mathrm{~km}$. No oceano Atlântico ela ocupa posição mediana, paralela às suas bordas. Foram decisivos os estudos paleomagnéticos do fundo oceânico, que permitiram a identificação e o mapeamento de bandas de anomalias magnéticas lineares alternadamente positivas e negativas, paralelas ao eixo das grandes cadeias. Indicavam que os fundos oceânicos vinham se expandindo por acréscimo, a um e outro lado delas, de rocha basáltica magnetizada de acordo com as variações das oscilações periódicas da polaridade magnética terrestre. As grandes cadeias oceânicas representavam bordas de placas litosféricas, algumas das quais arrastando fragmentos de crosta continental resultantes da ruptura de Pangéia. As porções equivalentes à litosfera assim acrescida voltavam ao manto por subducção em margens convergentes, oceânicas ou continentais, onde se desenvolviam fossas oceânicas, cadeias orogênicas e vulcânicas com províncias minerais e centros de intensa sismicidade causadora de desastres legendários. Com a aceitação da expansão dos fundos oceânicos surgia, em princípios da década de 1960, a teoria da Tectônica de Placas que abalaria os fundamentos então admitidos das ciências da Terra e viria criar a Geotectônica moderna.

Até então as maiores atenções dos geocientistas interessados na deriva dos continentes achavam-se voltadas principalmente para os oceanos. Comprovada a existência e expansão das placas litosféricas e conseqüente deriva, como sobre esteiras rolantes, dos blocos continentais nelas contidos, cresceu o interesse pelos estudos comparativos da história e estrutura dos continentes visando identificar possíveis conexões pretéritas. Foi nesse campo de

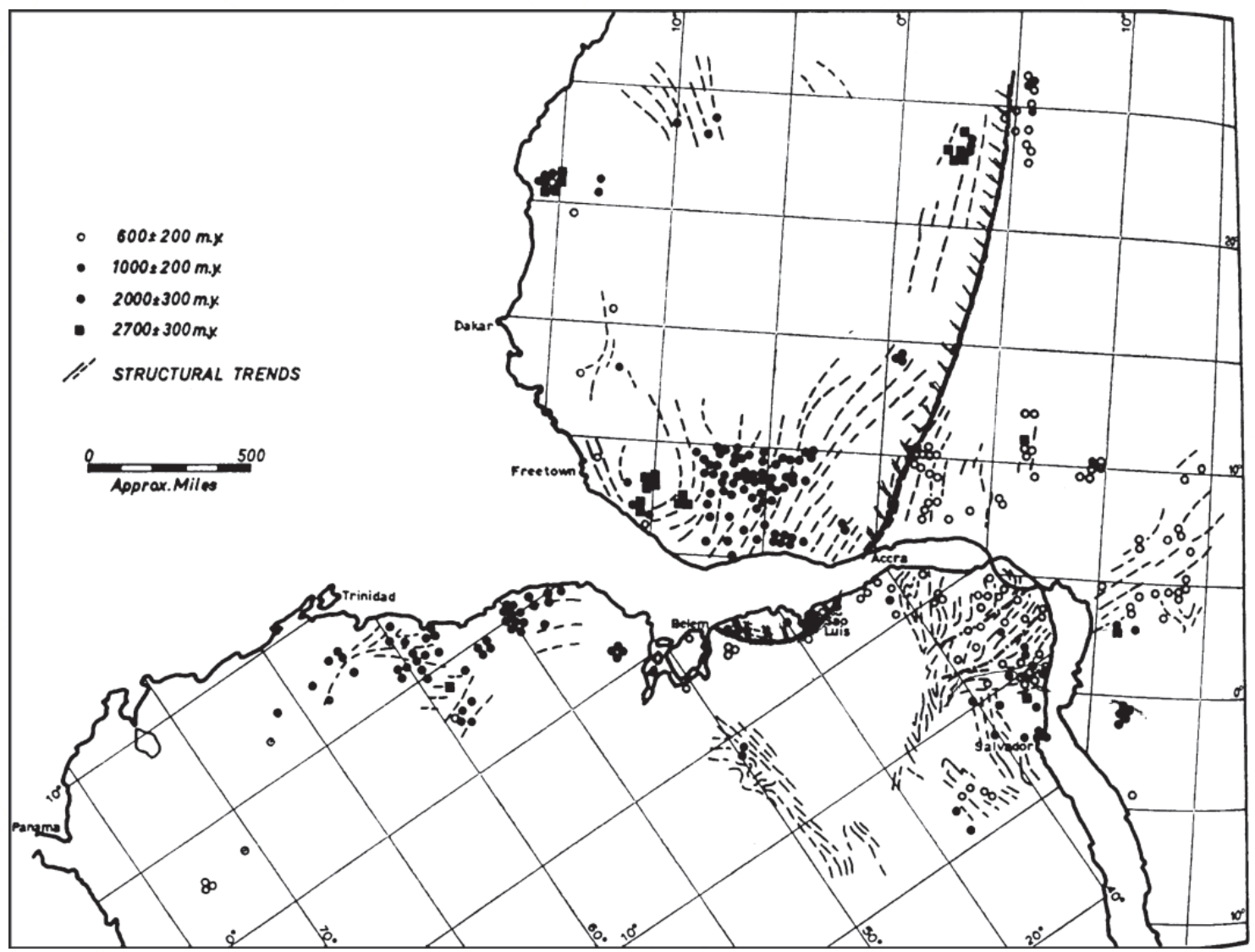

Figura 1 - Comparação de idades radiométricas Rb-Sr entre os ciclos orogênicos do Nordeste oriental com os da região adjacente na África (modif. de Hurley et al. 1967) 
estudos que a geologia brasileira teve destaque na grande revolução, com a execução de trabalhos de pesquisa comparativa com a África no decorrer da década de 1960 cujos resultados, divulgados em revistas de grande circulação nos meios científicos internacionais, muito contribuíram para a comprovação da teoria da Tectônica de Placas. Esta deixou de ser tida como mera teoria, mas foi proclamada como fato em reuniões realizadas nos Estados Unidos no inverno de 1966-1967, num simpósio no Goddard Institute for Space Studies, na American Geophysical Union e na Geological Society of América, a partir de quando passou a ser aceita pela grande maioria dos geólogos e geofísicos, embora com alguns renitentes contestadores, sobre-

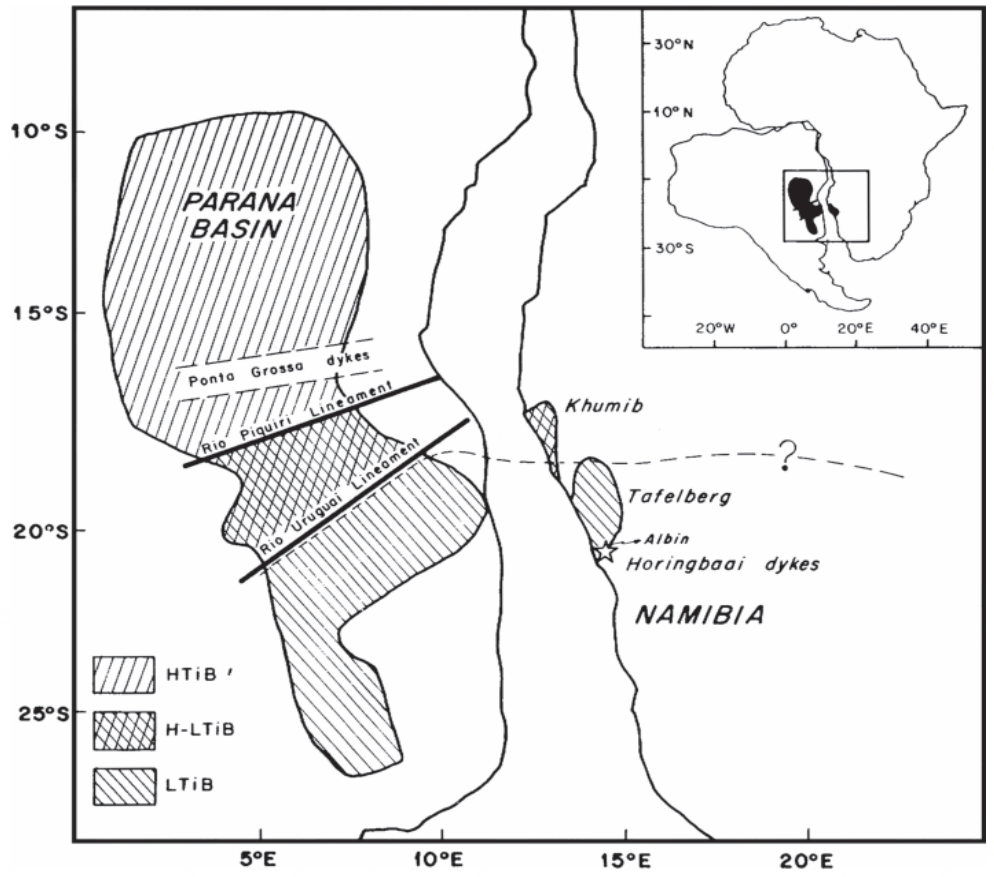

Figura 2 - Comparação da distribuição de rochas basálticas da Bacia do Paraná com os da região de Etendeka na África (modif. de McDougall \& Rüegg 1966) tudo na Europa e Ásia.

O Centro Paulista de Geocronologia (CPGeo) foi criado em 1964, tendo o professor U. G. Cordani, após curso de especialização no assunto em Berkeley, na Universidade da Califórnia, assumido a direção das pesquisas do laboratório, sendo ele próprio um ativo pesquisador. Os trabalhos de análises eram a princípio executados pelo professor de Física de Berkeley J. H. Reynolds, sucedendo-o o físico K. Kawashita e o geólogo G. Amaral. A. J. Melfi, P. Vandoros, G. Melcher, N. Rüegg e outros geólogos passaram a se interessar pela geocronologia e a contribuir com trabalhos sobre o assunto. Tendo sido eleito Presidente do Conselho Deliberativo do CPGeo pude acompanhar até 1972 o desenvolvimento dos principais programas de datação radiométrica, a princípio pelo método K-Ar.

Um dos primeiros programas foi desenvolvido pelo CPGeo em colaboração com o Massachusetts Institute of Technology (MIT). Tratava-se da comparação das idades pré-cambrianas do norte da América do Sul com as da África Ocidental visando verificar a possível ligação pretérita dos dois continentes. $\mathrm{O}$ programa era liderado pelo geocronólogo P. M. Hurley do MIT, cabendo a essa instituição realizar as análises $\mathrm{Rb}-\mathrm{Sr}$ e ao $\mathrm{CPGeo}$, as $\mathrm{K}-\mathrm{Ar}$. Os resultados obtidos em São Paulo foram originalmente apresentados em novembro de 1966 no Annual Meeting da Geological Society of América e publicados mais tarde no Brasil (Almeida e outros, 1968). Os resultados finais do programa foram divulgados em 1967 na revista Science tendo Hurley como autor principal e oito co-autores dos grupos CPGeo e MIT. Tiveram apreciável repercussão internacional por terem sido altamente sugestivos da ligação pretérita dos dois continentes, pois comprovavam a presença na região costeira do Maranhão, de um fragmento cratônico, mais tarde denominado Cráton de São Luís, que se ajustava ao Cráton do Oeste Africano como sua terminação sul se tivessem sido ligados os continentes. Também demonstravam excelente correlação de idades radiométricas e dos ciclos orogênicos do Nordeste oriental com os da região da África à qual teria sido adjacente (Fig. 1). Assim, as idades $\mathrm{Rb}-\mathrm{Sr}$ em rochas da orogênese Brasiliana, então chamada Caririana no Nordeste, adaptam-se a uma isócrona de $640 \mathrm{Ma}$ que também comporta valores representando a orogênese Pan-Africana obtidos em amostras da Nigéria.

Outro programa consistiu na determinação da idade dos basaltos e diabásios da bacia do Paraná para os quais, ainda em 1967, já haviam sido obtidas perto de uma centena de datações, quase todas acusando idades superiores a $120 \mathrm{Ma}$, do Cretáceo Inferior pré-Aptiano. Publicados os artigos em 


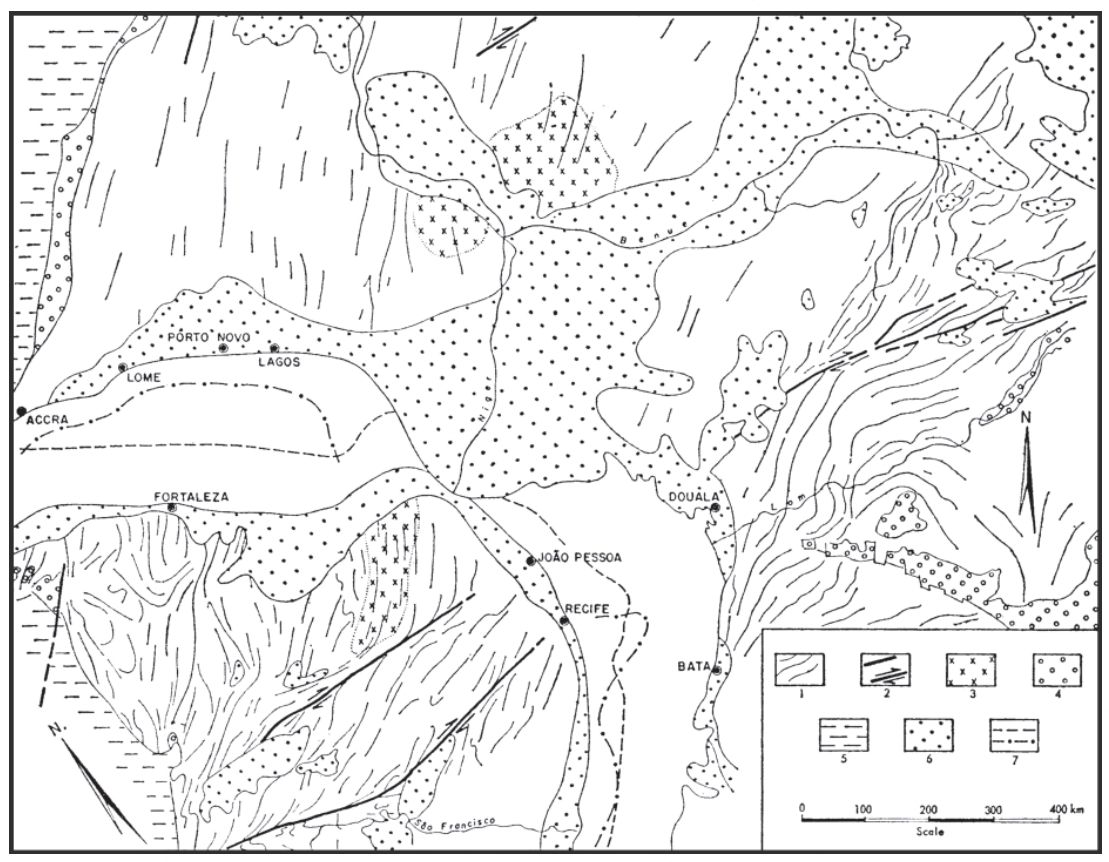

Figura 3 - Comparação geológica entre granitos da região da Nigéria com o Nordeste oriental brasileiro com os da região do Oeste africano (modif. de Almeida et al. 1965)

revistas científicas de circulação internacional, os principais devidos a Amaral e colaboradores (1966), McDougall \& Rüegg, (1966) e Melfi (1967), constituíram importante contribuição à muito debatida teoria da deriva dos continentes, por permitirem comparação com os derrames basálticos do planalto de Etendeka da região costeira da Namíbia no sudoeste da África. Estes eram então correlacionados aos basaltos do Karroo das regiões centrais e meridionais do continente, datados como sendo jurássicos, o que punha em séria dúvida sua correlação com os da Formação Serra Geral. Entretanto, logo após os derrames de Etendeka foram bem datados como sendo do Cretáceo Inferior. De tal modo eles também fariam parte da grande província magmática do Paraná, em maioria constituída de diques e derrames basálticos toleíticos de inundação e suas variedades intrusivas, precursores do início da separação dos dois continentes nessa latitude, se unidos tivessem sido (Fig. 2).

Em 1965 a UNESCO e a União Internacional das Ciências Geológicas (IUGS) convidaram um grupo de dez pesquisadores, do qual fiz parte, sendo cinco deles destacados especialistas em granitologia e os demais, dedicados à geologia regional, para se reunirem num colóquio itinerante com a finalidade de observarem os granitos e as estruturas regionais da Nigéria, Costa do Marfim e Camarões. Presidiu a reunião o professor E. Raguin da Escola de Minas de Paris, conhecido especialista em granitos. Vali-me da oportunidade para realizar uma comparação geológica da região que visitara com o que conhecia do Nordeste brasileiro e apresentei-a à UNESCO, que a publicou no mesmo ano em Paris, nos proceedings da reunião (Fig. 3). Dois anos após essas entidades convidaram o mesmo grupo para realizar um colóquio semelhante no nordeste do Brasil. Pertencia então ao Departamento Nacional da Produção Mineral e coubeme organizá-lo e presidi-lo com o apoio desta instituição e da SUDENE. Conclusões preliminares que obtive dessas observações e em colaboração com outro componente do grupo, o professor inglês R. Black, então na Universidade de Clermont-Ferran, França, grande conhecedor da geologia africana, apresentamo-las ao Simpósio sobre a Deriva dos Continentes com Ênfase na História do Atlântico Sul, promovido pela UNESCO/IUGS, que se realizou em Montevidéu em fins de 1967 sob a presidência do professor J.T. Tuzo Wilson da Universidade de Toronto, Canadá. Infelizmente os 84 trabalhos e resumos apresentados a essa reunião nunca foram publicados na íntegra e somente em 1972 Tuzo Wilson conseguiu publicar resumos de parte deles nos Transactions, American Geophysical Union.

Em co-autoria com Black publicamos nos Anais da Academia Brasileira de Ciências em 1968 um sumário do que observáramos nos dois continentes visando testar sua ligação pretérita. Entre outras conclusões preliminares de nossas observações 
conjuntas destacaram-se: história geológica e litologias précambrianas semelhantes; idênticas orientações dos alinhamentos estruturais do embasamento se unidos fossem os continentes, confirmando o que R. Pflug já havia observado em 1963; similaridade da idade e mineralização em tantalita, columbita, berilo e cassiterita das províncias pegmatíticas neoproterozóicas do norte da $\mathrm{Ni}$ géria e da região central do Rio Grande do Norte e Paraíba; aparente conexão entre as grandes faixas de cisalhamento transcorrente destral de Patos e Pernambuco com as de Ngaoundéré da região centro-norte da república dos Camarões, contendo intrusões de granitos alcalinos e hiperalcalinos em ambos os continentes; granitos sintectônicos comparáveis.

G. O. Allard, professor da Universidade de Georgia, e F.L. Humphrey, geólogos norteamericanos trabalhando para a Petrobrás no período 1959-1964, em companhia de outros geólogos dessa empresa identificaram uma faixa de dobramentos pré-cambrianos na borda nordeste do Cráton do São Francisco. Apresenta-se no Estado de Sergipe e adjacências de Alagoas e Bahia, sendo cruzada pela bacia tafrogênica de Tucano na Bahia. Caracterizou-a como uma faixa geossinclinal a que deu o nome de Propriá. Estende-se por $350 \mathrm{~km}$, orientando-se a $70^{\circ} \mathrm{NW}$. Nela reconheceram uma zona interna (eugeossinclinal), de maior metamorfismo (Grupo Vasa Barris), penetrada por rochas granitóides e uma externa (miogeossinclinal) representada pelo Grupo Miaba (Fig. 4). Os intensos dobramentos e menores falhas de empurrão indicavam vergência tectônica em direção ao Cráton do São Francisco, a sul. Uma cobertura tida como pré-cambriana tardia (Série Estância) estende-se discordantemente de sobre o Grupo Vasa Barris para sul, continuando-se sobre parte da área cratônica (Cráton do São Francisco). Essas estruturas, posteriormente conhecidas como faixa de dobramentos Sergipana, são interrompidas bruscamente em sua área aflorante pelas falhas que limitam a bacia costeira de Sergipe. Retornando aos Estados Unidos Allard decidiu viajar para a África, em companhia de seu colega de universidade professor V. J. Hurst para procurarem uma possível extensão do geossinclinal Própria, tendo reconhecido na Série Ndjolé, no Gabão, metassedimentos que consideraram correlacionáveis ao Grupo Vasa Barris, ao qual se equiparam em litologia, gradação metamórfica e tipos de deformações. Também a Série Ndjolé é recoberta discordantemente por sedimentos pré-cambrianos suborizontais que se assemelham a Estância e se apresentam no Gabão, Angola e Congo. Em trabalho que apresentaram ao Simpósio sobre a Deriva dos Continentes realizado em 1967 em Montevidéu, publicado na revista Science em 1969, Allard e Hurst enfatizaram a importância de sua descoberta como suporte à teoria da deriva continental.

G. Melcher e U. G. Cordani (1972) apresentaram ao referido simpósio de Montevidéu um trabalho em que sugeriram a correlação com base nas idades geocronológicas do Cráton do São Francisco com rochas similares do Gabão (Cráton do 
Congo). Também referiram que a então denominada faixa orogênica Paraíba fosse equivalente às rochas de mesma idade ( $\sim 500 \mathrm{Ma})$ da faixa Damarana da região costeira oposta da África.

Do que foi exposto evidencia-se o papel importante que tiveram as pesquisas geológicas realizadas no Brasil no decorrer da década de 1960 para a comprovação da deriva dos continentes. No Simpósio de Goddard em 1966, entre os 16 trabalhos então apresentados o da correlação das províncias geocronológicas do norte da América do Sul com as da África Ocidental feita por P. M. Hurley e J. R. Rand, em grande parte comprovada pelas pesquisas conjuntas realizadas pelo CPGeo e MIT, teve importante impacto no reconhecimento da realidade da Tectônica de Placas. Esta também foi suportada pelos resultados de outras pesquisas realizadas no Brasil durante a segunda metade da década de 1960, indicando que estruturas précambrianas como os limites dos crátons de São Luís e São Francisco, as grandes faixas de cisalhamento de Pernambuco e Patos, os alinhamentos das estruturas neoproterozóicas e a faixa de dobramentos Sergipana, assim como os derrames basálticos eocretáceos da bacia do Paraná apresentavam continuidade na África Ocidental numa fase que precedeu a deriva dos continentes.

Tal foi a contribuição dos geólogos brasileiros para a grande revolução das geociências que deu origem à moderna Geotectônica com todas as suas conseqüências.

\section{Referências}

Allard, G.O. \& Hurst, V.J. 1972. New tectonic discoveries in Brazil and their counterparts in Gabon. Continental Drift Emphasizing the History of South Atlantic Area. Am. Geophys, Union, Trans., 53:177.

Allard, G.O. \& Hurst, V.J. 1969. Brazil-Gabon geologic link supports continental drift. Science, 163:528-532.

Almeida, F.F.M.de. 1965. Precambrian geology of North-eastern Brazil and Western Africa and the theory of continental drift. Symposium on the Granites of the West Africa, Ivory Coast, Nigeria and Cameroon. Proc... Paris: Unesco. p. 151-162.
Almeida, F.F.M.de; Melcher, G.C.; Cordani, U.G.; Kawashita, K. e Vandoros, P. 1968. Radiometric age determinations from Northern Brazil. Bol. Soc. Bras. Geol., 17(1):3-14.

Almeida, F.F.M.de \& Black, R.. 1968. Geological comparison of Northeastern South America and Western África. An. Acad. Brasil. Ciên., 40(Supl.): 317-319.

Almeida, F.F.M.de \& Black. R. 1972. Comparaison structurale entre le N.E. du Bresil et l'Ouest Africain. Continental Drift Emphasizing the History of the South Atlantic Área. Amer. Geophys. Union, Trans., 53:177.

Amaral, G.; Cordani, U. G.; Kawashita, K.;Reynolds, J.H.. 1966. Potassium-argon dates of basaltic rocks from Southern Brazil. Geochim. Cosmochim. Acta, 30:159-189.

Du Toit, A.1927. A geological comparison of South America with South Africa. Washington D.C.: The Carnegie Institution Publ. 381, 157 p.

Hurley, P.M.; Almeida, F.F.M.de; Melcher, G.C.; Cordani, U.G.; Rand, J.R.; Kawashita, K.; Vandoros, P.; Pinson, W.H.; Fairbairn, H.W. 1967. Test of Continental Drift by Comparison of Radiometric Ages. Science. 157(3788):495-500.

Hurley, P.M.1968. The Confirmation of Continental Drift. Sci. Amer., Abril 1968:52-64.

McDougall, I \& Rüegg, N.R. 1966. Potassium-Argon dates on the Serra Geral Formation of South America. Geochim. Cosmochim. Acta, 30:191-195.

Melcher, G.C. \& Cordani, U.G. 1972. A Geochronological Comparison of West Africa and South American Basement. Amer. Geophys. Union, Trans., 53:178.

Melfi, A. J. 1966. Potassium-Argon ages for core samples of basaltic rocks from Southern Brazil. Geochim. Cosmochim. Acta, 31:1079-1089.

Pflug, R. 1963. Präkambrische Strukturem in Afrika und Südamerika, eine Gegenüberstellung. Stuttgart: N. J. Geol., Paläeont., 7, 355-358.

Suess, E. 1895. Das Antlitz der Erde. Temmsky, Wien.

Wegener, A.L. 1915. Die Entstehung der Kontinente und Ozeane. Brauschweig: Friedrich Vieweg und Sohn.

Submetido em março, aceito em abril de 2005. 